\title{
Impact of the Teaching Techniques on the Distruptive Behaviour
}

\author{
Dr. Alma Muharremi \\ "Aleksandër Xhuvani" University, Elbasan, Albania, Faculty of Education Sciences, Department of Teaching Methodology \\ almamuharremi@gmail.com
}

\section{Doi:10.5901/mjss.2015.v6n2s1p69}

\begin{abstract}
The disruptive behaviour of students and the impact that the teaching techniques may have on it are an important issued for the Albanian school. One of the techniques that has new the tendency to be used in the Albanian education is the Respond Cards (RC) Technique. This technique offers students plenty of opportunities to interact when they are learning a new material, or when repeating a material learned before. It also enables teachers to assess the understanding of each student, react instantly and adapt the lesson and the class to the circumstances. The goal of this study is to assess the impact that using the RCs Technique in the class of Knowledge on the Nature will have on the students' disrupting behaviour. The RCs Technique was used in combination with the Single-Student Responding (SSR) Technique through an ABAB type design. Five students of the fourth grade in the "Ali Agjah" school in Elbasan, Albania were the sample for the data collection. The disruptive behaviour was measured during SSRs and RCs, by partial intervals' recording in the observation of each student in each session. Results showed that when RCs were used the average number of intervals with disruptive behaviour fell by 5.4 and that there were no differences between genders. It is not only productive, but also essential and indispensable to implement effective instructing techniques such as RCs, which highly evaluate the active responses of the students. Teachers must deal with disruptive behaviour, but they also should see deep in their teaching techniques.
\end{abstract}

Keywords: disrupting behaviour, ABAB design, techniques of Response Cards, Single-Student Responding, Knowledge on the nature.

\section{Introduction}

The overall problems caused by disruptive behaviour are highlighted in the studies of Steed and Lawrence (1988), Gray and Richer (1988), Sentelle (2003), Jung e Boman (2003), Hunter-Love (2008), Hofstadter-Duke (2011) Todras (2007) and many others, and they are present in the Albanian education system too. More than half of Albanian teachers complain about the problematic behaviour of students (Tamo \& Karaj, 2007).

The students' disrupting behaviour and the impact that the teaching techniques may have on it are an important issued for the Albanian school. One of the techniques that has the new tendency to be used in the Albanian education is the Respond Cards (RC) Technique. This technique offers students plenty of opportunities to interact when they are learning a new material, or when repeating a material learned before (Randolph, 2007; Sutherland et al, 2002). RCs enable teachers to assess the understanding of each student, react instantly (Christle \& Schuster, 2003) and adapt the lesson and the class to the circumstances (Kellum, Carr \& Dozier, 2001). RCs are reusable tables which allow all students to independently answer questions of the teacher (Cavanaugh et al, 1996; Gardner et al, 1994).

Different researchers have highlighted the benefit of using the RCs technique in reducing disruptive behaviour. Use of RCs is an intervention with some empirical evidence aiming at reducing disrupting behaviour, while positive behaviour in class increases (Lambert et al, 2006).

Armendariz \& Umbreit (1999) were the first to obtain the effects of the empirical examination of the RCs of the disruptive students. They reported a considerable reduction of the intervals with disrupting behaviour when using RCs, compared to the questions-answers classes. All 22 students involved in the research reduced their disrupting behaviour to $59 \%$ when using RCs.

Christle \& Schuster (2003) assessed the effects of RCs on the participation, academic performance and behaviour of students of the fourth urban grade during instructions in maths. Percentage of intervals of on-task behaviour increased for all five students with one student increasing from $12.5 \%$ during hand raise condition to $100 \%$ during the RC condition.

Lambert el al (2006) proved the effects of RCs on the reduction of disrupting behaviour and on the increase of academic responses during the maths class for nine students of the fourth grade in an urban school. Disruptive behaviour decreased from a $\mathrm{M}=6.8 \%$ (range $5.6 \%$ to $8.0 \%$ ) during hand raise condition to a $\mathrm{M}=1.3 \%$ (range $0 \%$ to $2.7 \%$ ) during $\mathrm{RC}$ condition, for an overall average decrease of $5.5 \%$ disruptive behaviour. 
The goal of this research is to assess the effects that the use of RCs technique during the class of Knowledge on the Nature have on the disrupting behaviour of the students. It also aims to find out if there are gender differences in the disrupting behaviour when using RCs technique.

The questions raised by this research are:

Do students display less disrupting behaviour when the RCs technique is used?

Are there gender differences in the disrupting behaviour when the RCs technique is used?

\section{Method}

\subsection{Participants and data}

The research was conducted in the fourth grade of the "Ali Agjah" school in Elbasan, in the class of Knowledge on the Nature, which is taught in three classes a week. The school and the class were chosen randomly. The sample for data collection was 5 students who were chosen by the researcher and the teacher of the class, after the researcher observed the class for 2-3 classes a week during a month and identified them as student with disrupting behaviour. These student were 9-10 years of age, and their grades in the subject were 5,6 and 7 (the lowest passing grade in the Albanian education system is 5 , and the highest is 10). $40 \%$ of the sample were girls and $60 \%$ boys. Their data are presented in Table 1.

Table 1: Demographic and Academic data of Target Students

\begin{tabular}{|c|c|l|c|}
\hline Student & Gender & Age & Grade in the subject of Knowledge on Nature \\
\hline 1 & M & 9 years and 3 months & 6 \\
\hline 2 & F & 9 years and 7 months & 5 \\
\hline 3 & M & 9 years and 1 month & 5 \\
\hline 4 & F & 9 years and six month & 7 \\
\hline 5 & M & 10 years & 6 \\
\hline
\end{tabular}

The teacher holds the Bachelor Degree "Teacher of grades 1-4", has obtained the "Very well" grade in the second level of qualification, and has been teaching all subjects of the fourth grade curriculum - including Knowledge on the Nature - for 15 years.

\subsection{The project of the research and the procedures.}

An ABAB type design was used, which means:

A- Use of Single-Student Responding (SSR1)

B- Use of Responding Cards (RC1)

A- Use of Single-Student Responding (SSR2)

B- Use of Responding Cards (RC2)

This design type means that the disrupting behaviour will be measured during four sessions during which SSRs and RCs will be used consecutively, and the aim will be to find out whether there are differences in the disrupting behaviour of the students during SSRs compared to RCs.

The use of the SSR technique consists in students being allowed to answer the teacher's questions after they raise their hands. The class was characterised by typical classroom procedures, like introduction of new knowledge, independent work, and the creation of practical skills by using the question-answer format. The accuracy of the answers of the five students were corrected in some cases.

The use of the RCs technique consisted in each student using a card to write their answer to the teacher's question, and then showing it. The cards in the class of Knowledge on the Nature contained questions to which student could reply with "True/False" or by choosing alternatives, and also open questions. When the teacher asked a question to the class, students were given 3 seconds to think about the answer, time to write the answer, and then students raised their hands to give their answer, thus allowing the teacher to quickly check the class and assess the understanding of each student.

The teacher, who did not have previous knowledge on the RCs Technique, received a training which focused on knowing the essentials and characteristics of the RCs technique and on mastering the skill to use it in class. 
The use of SSR and RCs techniques was applied several times during a month by the teacher, so that students would familiar with them. No measuring was performed during this period.

\subsection{The observation procedure}

The research team consisted of the researcher and his 4 assistants. The assistants were students on master in education, and they were present during the Knowledge on the Nature class. The disrupting behaviours were recorded through direct observation. Each assistant observed one student and kept notes of their disrupting behaviours (if any). Students were not aware that they were being observed.

Observers and students were given codes from 1-5 and they kept these codes until the end of the study. Each observer recorded the disrupting behaviours of one designated student, using a recording procedure with partial intervals. Each participant student was observed for 10 seconds, and then 5 seconds were used for recording. A wall mounted electronic clock was used so that observers were in sync during observations in 10 seconds intervals.

\subsection{Research instrument}

The instrument used in this study was a table for the recording of disrupting behaviours and was built by adapting instruments of Gable et al (1998). Observers had recording cards with observation intervals. If the student displayed disrupting behaviour during an observation interval, the interval was coded as disruptive $(+)$. If no disrupting behaviour was displayed, the interval was coded 0.

\subsection{Defining and measuring the variables}

The variables in this study are: disrupting behaviour (dependent variable), the techniques of RCs (independent variable), and the technique of SSRs (independent variable). The operational definition of the variables in this study was:

Disrupting behaviour in class is a behaviour which prevents or obstructs the teaching and learning process (De Martini-Scully et al, 2000).

In the RCs technique each student independently writes his/her answer to the teacher's question and then shows

it.

In the SSRs technique each student asks permission to answer the teacher's question.

\section{Results}

The first research question: Do students display less disrupting behaviour when the RCs technique is used?

The disrupting behaviours of five students during the Knowledge on the Nature class were observed in alternated SSR and RC intervals. Data on intervals of disrupting behaviour for each student (Table 2) show that:

Student 1 reduced by 6.1 the average number of intervals with disrupting behaviour when passing from SSR1 session ( $M=7.3$ ) to RC1 $(M=1.2)$, and an even greater reduction (6.7) when passing from SSR2 $(M=8.7)$ to RC2 $(M=$ 2.0). His overall reduction of the average number of intervals with disrupting behaviour was 6.4 when passing from SSR session ( $M=8.0)$ to the $R C$ session ( $M=1.6)$. Student 1 displays less disrupting behaviour when the RCs technique is used.

Student 2 reduced by 7 the average number of intervals with disrupting behaviour when passing from SSR1 session ( $M=7.5)$ to RC1 $(M=0.5)$. The reduction was smaller (5.4) when passing from SSR2 $(M=7.9)$ to $R C 2(M=$ 2.5). His overall reduction of the average number of intervals with disrupting behaviour was 5.2 when passing from SSR session ( $M=7.7)$ to the $R C$ session $(M=1.5)$. Student 2 displays less disrupting behaviour when the $R C$ s technique is used.

Student 3 reduced by 5.3 the average number of intervals with disrupting behaviour when passing from SSR1 session $(M=7.7)$ to RC1 $(M=2.4)$. The reduction was smaller $(5.1)$ when passing from SSR2 $(M=7.4)$ to RC2 $(M=$ 1.3). His overall reduction of the average number of intervals with disrupting behaviour was 5.7 when passing from SSR session ( $M=7.5)$ to the $R C$ session $(M=1.8)$. Student 3 displays less disrupting behaviour when the RCs technique is used.

Student 4 reduced by 5.4 the average number of intervals with disrupting behaviour when passing from SSR1 session $(M=6.4)$ to RC1 $(M=1.0)$. The reduction was smaller (2.8) when passing from SSR2 $(M=4.0)$ to RC2 $(M=$ 1.2). His overall reduction of the average number of intervals with disrupting behaviour was 4.1 when passing from SSR 
session ( $M=5.2)$ to the $R C$ session $(M=1.1)$. Student 4 displays less disrupting behaviour when the RCs technique is used.

Student 5 reduced by 5.3 the average number of intervals with disrupting behaviour when passing from SSR1 session ( $M=5.9)$ to RC1 $(M=0.6)$. The reduction was smaller (3.9) when passing from SSR2 $(M=5.4)$ to RC2 $(M=$ 1.5). His overall reduction of the average number of intervals with disrupting behaviour was 4.6 when passing from SSR session $(M=5.6)$ to the $R C$ session $(M=1.0)$. Student 5 displays less disrupting behaviour when the RCs technique is used.

Table 2. Mean Number of Intervals of Disruptive Behavior during SSR and RC conditions for the target students

\begin{tabular}{|l|c|c|c|c|}
\hline Student & SSR1 & RC1 & SSR2 & RC2 \\
\hline Student 1 & 7.3 & 1.2 & 8.7 & 2.0 \\
\hline Student 2 & 7.5 & 0.5 & 7.9 & 2.5 \\
\hline Student 3 & 7.7 & 2.4 & 7.4 & 1.3 \\
\hline Student 4 & 6.4 & 1.0 & 4.0 & 1.2 \\
\hline Student 5 & 5.9 & 0.6 & 5.4 & 1.5 \\
\hline Group(M) & 6.9 & 1.1 & 6.7 & 1.7 \\
\hline
\end{tabular}

Note. SSR = single-student responding; $\mathrm{RC}=$ response cards.

When passing from SSR1 to RC1, Student 2 had the greatest reduction $(M=7)$ of the average number of disrupting behaviour intervals (see Table 2), and students 3 and 5 had the smallest reduction ( $M=5.3$ ). When passing from SSR2 to CR2, Student 1 had the greatest reduction $(M=6.7)$ of the average number of disrupting behaviour intervals, and students 4 had the smallest reduction $(M=2.8)$. Student also had the greatest reduction of the average number of disrupting behaviour intervals $-M=6.4$ - when passing from SSR to RC. Student 4 had the smallest reduction of the average number of disrupting behaviour intervals - $M=4.1$ - when passing from SSR to RC.

For all involved students, the difference between average number of intervals with disrupting behaviours during SSR1 $(M=6.9)$ and SSR2 $(M=6.7)$ is 0.2 . So it can be said that student display almost the same number of intervals with disrupting behaviour during these sessions. The difference between average number of intervals with disrupting behaviours during RC1 $(M=1.1)$ and $R C 2(M=1.7)$ is 0.6 .

For all involved students, the difference between average number of intervals with disrupting behaviours during SSR1 $(M=6.9)$ and RC1 $(M=1.1)$ is 5.8. Student 5 had the greatest reduction. All five disruptive students increased the average number of intervals with disrupting behaviours when passing from RC1 to SSR2. Student 1 had the greatest increase, exceeding SSR1 session. All students indicated a reduction of disrupting behaviour when passing from SSR2 to $\mathrm{RC2}$. This is a considerable reduction that highlights the efficiency of using the RCs technique, which is confirmed by the other reduction (by 5 ) of the number of intervals with disrupting behaviours when passing from SSR2 (M =6.7) to RC2 ( $M$ $=1.7$ ). The greatest reduction of intervals with disrupting behaviours happens during the first passing from SSR to RCs.

The behaviour of the disruptive student varied between a middle and low level when using RCs. Disrupting behaviour declined during the RC1 session, increased during SSR2, and declined again during RC2. The overall average reduction of number of intervals with disrupting behaviours for all involved students was 5.4 , with $M=6.8$ during SSR and $M=1.4$ during $\mathrm{RC}$.

So, less disrupting behaviours were displayed when RCs technique was used.

The second research question: Are there gender differences when using the RCs technique?

The sample was $40 \%$ girls and $60 \%$ boys. This ratio does not match the real ratio in the class, where $70 \%$ are girls and $30 \%$ boys.

Both girls and boys involved in the research (See Table 2) had same average number of intervals with disrupting behaviour during SSR1 (6.9). Boys $(M=1.4)$ had 0.7 more intervals with disrupting behaviour than girls $(M=0.7)$ during RC1. This difference goes up to 1.3 during SSR2. But in RC2 girls had 0.2 more intervals with disrupting behaviours than boys.

Girls had a decline of 6.2 in the average number of intervals with disrupting behaviours when passing from SSR1 $(M=6.9)$ to RC1 ( $M=0.7)$. The reduction for girls was smaller (4.1) when passing from SSR2 ( $M=5.9)$ to RC2 $(M=1.8)$. The overall reduction of intervals with disrupting behaviours for girls was 5.2 when passing from SSR $(M=6.4)$ to RC (M $=1.2$. .

Boys had a decline of 5.5 in the average number of intervals with disrupting behaviours when passing from SSR1 $(M=6.9)$ to RC1 ( $M=1.4)$. The reduction for boys was greater $(5.6)$ when passing from SSR2 $(M=7.2)$ to RC2 $(M=$ 
1.6). The overall reduction of intervals with disrupting behaviours for boys was 5.5 when passing from $S S R(M=7.0)$ to $\mathrm{RC}(\mathrm{M}=1.5)$.

There was an insignificant difference in the average number of intervals with disrupting behaviour between girls (5.2) and boys (5.4) when passing from SSR1 to RC1. When passing from SSR2 to RC2 boys had in average 1.5 more intervals with disrupting behaviours than girls. The difference was insignificant when passing from SSR to RC sessions, with $M=5.2$ for girls and $M=5.0$ for boys.

So, there were no gender differences when using RCs technique.

\section{Discussion}

The research results showed that less disrupting behaviours happen when RCs technique is used in the class of Knowledge on the Nature and that there are no gender differences when this technique is used.

A summary of the data for each student provides a good argument for the prediction, verification and the recurrence of the positive effects of the RCs on the disrupting behaviour of students. All students displayed a considerable decline of disrupting behaviours during RCs sessions compared to SSR sessions. Musai notes that such problems (disrupting behaviours) can be considerably reduced through quality teaching in general, and in particular through the way of behaving the working system of the teacher.

The research results indicate a functional relation between the dependent variable (disrupting behaviour) and the independent variable (Response Cards). Students showed higher level of disrupting behaviour during SSR compared to RCs sessions. It has been accepted that teaching methods influence the disrupting behaviour of the students (Krounin 1970).

As Lambert et al (2006) note, these findings are in line with previous researches for the fact that the implementation of effective instructive strategies such as the RCs, which highly evaluate active responses of the students, is not only productive, but also essential and indispensable.

Furthermore, these results are supported by research in certain areas of learning and by the positive effects of direct instructive strategies, especially for urban teachers from Bullara (1994) and Delpit (1995).

The research results showed that all five disruptive students were less disruptive during RCs sessions. Lambert et al (2006) note that during the last years a lot of debate has focused on the approach to effective instructions to students, but the impact of these approaches rarely goes along with this discussion.

This is an important consideration which deserves critical attention in the Albanian education context.

Techniques like RCs get students involved, so they are required to take an active role in the instructions. For students, being more attentive with the instructions means more learning and less distraction from other factors in class, and less time for disrupting behaviour. Using RCs also allows teachers to receive distinguishable answers from students, and as a result they can continuously have immediate feedback on the students' performance, which also increases the learning of the students. Teachers must get familiar with techniques like RCs and make them part of their work.

\section{References}

Armendariz , F. , \& Umbreit, J. (1999). Using active responding to reduce disruptive behaviour in a general education classroom. Journal of Positive Behaviour Interventions, 1(3).

Bullara, D.T.(1994). Effects of guided notes on the academic performance and off-task/disruptive behaviors of students with severe behavior handicaps during science instruction. Unpublished doctoral dissertation, The Ohio State University.

Cavanaugh, R. A., Heward, W. L., \& Donelson, F. (1996). Effects of response cards during lesson closure on the academic performance of secondary students in an earth science course. Journal of Applied Behavior Analysis, 29, pp. 403-406.

Christle, C. A., \& Schuster, J. W. (2003). The effects of using response cards on student participation, academic achievement, and ontask behavior during whole-class, math instruction. Journal of Behavioral Education, 12, pp. 147-165.

Delpit, L. (1995). Other people's children. New York; The New Press.

DeMartini-Scully, D., Bray, M. A., \& Kehle, T. J. (2000). A packaged intervention to reduce disruptive behaviours in general education students. Psychology in the Schools, 37(2), pp. 149-156.

Gable, R. A., Quinn, M. M., Rutherford, R. B., Jr., \& Howell, K. W. (1998). Functional behavioral assessments and positive behavioural interventions. Preventing School Failure, 42, pp. 106 - 119.

Gardner, III, R., Heward, W. L., \& Grossi, T. A. (1994). Effects of response cards on student participation and academic achievement: A systematic replication with inner-city students during whole-class science instruction. Journal of Applied Behaviour Analysis, 27, pp. 63-71.

Gray, J. and Richer, J. (1988). Classroom Responses to Disruptive Behaviour, Macmillan Education.

Hunter-Lowe, M.R. (2008). Qualitative Analysis of Disruptive Behavior and Leadership Influence in Two Urban K-6 Virginia Elementary 
Public Schools. Universal-Publishers, Disertation.com Boca Raton, Florida USA.

Hofstadter-Duke, K. L. (2011). Functional analysis of replacement behavior: assessing concurrent behavioural excesses and academic deficits , University of Nebraska. http://digitalcommons.unl.edu/cgi/viewcontent.cgi?article=1110\&context=cehsdiss

Jung, J. \& Boman, P. (2003). Comparison of disruptive behaviours in South Australian LOTE and mainstream primary school classrooms, Journal of Educational Enquiry, Vol. 4, No. 2, pp. 90-101.

Kellum, K. K., Carr, J. E., \& Dozier, C. L. (2001). Response-card instruction and student learning in a college classroom. Teaching of Psychology, 28, pp. 101-104.

Kounin, J. (1970). Discipline and group management in classrooms. New York: Holt, Rinehart \& Winston, Cituar nga Orlich, C. et al. (1995). Learning Strategies (Strategjitë e të mësuarit), Eureka, Tiranë, pp. 318, 319.

Lambert, M. C., Cartledge, G., Heward, W. L., \& Lo, Y. (2006). Effects of response cards on disruptive behaviour and academic responding during math lessons by fourth-grade urban students. Journal of Positive Behaviour Interventions, 8, pp. 88-99.

Musai, B. (2003). Teaching Methodology (Metodologji e mësimdhënies). Tiranë: Pegi, f. 222.

Randolph, J. J. (2007). Meta-analysis of the research on response cards: Effects on test achievement, quiz achievement, participation, and off-task be. Journal of Positive Behaviour Interventions, 9, pp. 113-128.

Sentelle, J. (2003). A multi-component behavioural intervention for a diverse classroom, Dissertation, School of The Ohio State University, pp. 62.

Steed, D. and Lawrence, J. (1988). Disruptive Behaviour in the Primary School, Goldsmiths' College, University of London.

Sutherland, K. S., Wehby, J. H., \& Yoder, P. J. (2002). Examination of the relationship between teacher praise and opportunities for students with EBD to respond to academic requests. Journal of Emotional and Behavioral Disorders, 10, pp. 5-13.

Tamo, A., Karaj, Th. (2007). Study: Job satisfaction of the Albanian teachers (Kënaqësia e mësuesve shqiptarë nga puna e tyre), pp. 18.

Todras, P. (2007). Teachers' perspectives of disruptive behaviour in the classroom. The Chicago School of Professional Psychology, Dissertation. 